\title{
New Type of Community Sports in Building a Harmonious Society
}

\author{
Kun Liu ${ }^{1, a}$, Na Liüb
}

${ }^{1} \mathrm{PE}$ Department of Jiangxi University of Traditional Chinese Medicine, Nanchang 330004, China

aliuk0791@163.com, b329022334@qq.com

Corresponding author: Na Liu

Keywords: Community sports, Harmonious society, Sports ground

\begin{abstract}
Using the method of literature review and investigation method, in view of the current lack of community sports venues, imperfect laws and regulations is not sound, sports management organization, shortage of funds, such as sports instructors vacancy problem, puts forward some specific solutions. The practice of these measures will greatly promote the development of community sports, accelerate the progress of harmonious society.
\end{abstract}

\section{Introduction}

The party's fourth plenary of sixteen session put forward the requirement of building a harmonious socialist society, harmonious society and social politics, economy, culture, sports, such as the mutual promotion and common development. Sports in building a harmonious society also plays an important role in improving the physical education and health level of the Chinese nation, is bound to a positive impact on building a harmonious socialist society. And the community as a human life is the most basic social unit, the development of the society, in fact, is based on the development of the community, as the main body of community sports community culture undoubtedly played a prominent role in community development, but a series of problems still exist in the field of sports community sports, these problems influence the comprehensive development of sports, which restricts the harmonious social process. Therefore, solving the problem of good community sports, on the one hand, be helpful for the national fitness health, is beneficial to the harmony, is beneficial to the comprehensive development of sports, to promote the development of harmonious society; Affinity through sports culture form, on the other hand, interpersonal relationship and cultivate the national spirit, man and society, the goal of harmony between human and nature, to promote community sports culture prosperity also has practical significance.

\section{The current situation of community sports and the existing problems}

\section{Community can not make full use of the stadium.}

Stadium is usually public sports installations and facilities of a city, but because is the government funding, always USES is closed management mode, make these facilities utilization ratio is low, in addition to some large sports or activities, rarely normally open to the community, idle for a long time.

Community sports venue relatively scarce.

As of December 31, 2003, the end of the fifth national sports ground survey of China's bubble around nationally, in addition to Taiwan, Hong Kong, Macao, the various forms of ownership system, industry, hong has meet the requirements of the fifth national sports ground survey of all kinds of sports, 850080, for the development of mass sports in China laid a good foundation. But at the same time should see, on average every ten thousand people in China have sports venues 6.5 to 8 , sports venues per capita area.

Square metre, the absolute number of sports facilities and the per capita possession of sports venues are still less, with some overseas sports developed countries there is still a large gap.

Can be seen from the ground survey, the current community sports activities, one of the obstacles is short facilities, community sports venues (27.66\%, authority of the enterprises and 
institutions, XiangZhen Village, residential area and industrial field, parks, residential area, the old square. This kind of condition can limit the content of community sports activity, activity time, influence the comprehensive development of community sports. School sports venues of $67.7 \%$, and the opening to the outside of the situation is not optimistic, and need to be further improved.

\section{Sports management organization is not sound.}

Sports organization and management from the point of the organizational structure, multi-level community sports organizations has not been set up, can't stratified sports work, administrative color is strong, the organization is not enough diversity in form, with the current contradiction diverse society is outstanding, the community sports organizations adopt one-way management mode, lack of interactive factors, management process and the lack of supporting services, the potential of organization system can not get into full play.

\section{The laws and regulations is not sound.}

Around the current our country community sports development is not very standard, community sports development is not balanced, although the "sports law" of our country sports normal specification area, but it is only a method, the lack of specific and effective of the actual situation of each place.

\section{The strategy to solve the problem of community sports}

Perfect laws and regulations, standardize the community sports.

Around should be in on the basis of the education law, work out for the fact of the local laws and regulations and establish the authority of community sports organizations, make clear a regulation of community sports facilities and sources of funds, to ensure that everyone involved in the power of the community sports. Such as to develop a Shared community and school sports ground rules, an acceptable period of time in school and community, school sports venues open to the community, community sports equipment is also open to the school at the same time, this is a successful experience of the development of community sports in the European and American countries. Only in this way can we truly reflects the "everyone to participate in, everyone enjoy the community sports idea, to guide the healthy development of community sports and harmonious.

Develop the sports instructors, and promote the harmonious development of community sports.

Role, such as coaches, mentors, referees, promotion and popularization of community sports play an important role in the process. But, our country social sports instructors and the proportion of the population compared to European and American countries, also have quite a big gap, because of the development of the sports instructor system in developed countries and regions have already quite mature, has not been reflected in our country. Therefore, according to the needs of the development of community sports, to cultivate the community sports instructors, not only pay attention to the increase of the number, but also to constantly improve the level of their business, to establish a stable community sports guidance team. Way, of course, can be varied, such as cultivated by colleges and universities.

A higher level of social sports instructors, also can fully mobilize social forces, absorb has certain specialty and enthusiastic social public welfare activities, through certain qualification.

Do perfect the sports management organization, ensure the healthy development of community sports.

Current our country community sports lack of effective management organization, this will seriously affect the normal development of community sports in China. Therefore, as soon as possible to establish a set of management organizations of community sports activity, is an effective way to promote the healthy development of community sports in China. According to our country's administrative division habits, can be divided into national, provincial, municipal and county (district) level, township c) level 5 community sports management institutions. National and provincial management institution shall be responsible for the macro level, such as the state council.

Community sports policy, policy, strategy, strategy; Municipal and county (district) management organization responsible for the medium level, such as to assist the macro 
management organization to make decisions, to carry out the macro management organization for the development of policy, policy, strategy, tactics, according to the situation of community sports in this area, make a medium level of the arrangement; Township grasp the superior spirit, to carry out the community sport specific work, such as sports venues, sports facilities, etc., to conduct regular community sports entertainment activities. All levels of management organization, individual, cooperate with each other, coordinate with each other, forming a harmonious sound and stable management system, to create good conditions for the development of community sports.

\section{large sports venues and affiliated facilities open to the community.}

Large sports venues idle with today's socialist market economy, reform is imperative. In 1995, the original national sports commission issued "notice about public sports venues open to the masses of Lin qun word [1995] no. 1995 days request the administrative department for physical culture and sports to the local people's governments at various levels shall, under the leadership of the planed, organized, orderly public sports venues open to the community as soon as possible all; Explore to adapt to the socialist market economy system step by step the new way of community sports socialization, on the premise of good social benefit, the existing public sports venues in principle to free open to the community, sports venues and facilities can be a service gratis, at the same time, some supporting economy service activities; Strengthen scientific management, and constantly improve the efficiency of the existing sports venues. On the development of community sports, change the existing sports venues ", rely on, such as "thought, realize" games to raise ", promote the harmonious development of society.

\section{Conclusions}

On December 31, 2003, the end of the fifth sports ground survey, the results show that the lack of sports facilities in our country, the community sports is short, sports venues per capita is less than 1. 3 square metre. Aiming at a series of problems of community sports, only to take the school sports facilities and stadium facilities open to the school; Perfect laws and regulations, standardize community sports; Perfect the sports management organization, to ensure the healthy development of the community sports; To raise funds, solve community Education funding shortage; A series of measures such as developing sports instructors, to promote the harmonious development of community sports, and speed up the harmonious society to go forward.

\section{References}

[1] Ye xiaowen. "creating human destiny community" of China as a global superpower Power support at [J]. People's BBS, 2015 (34).

[2] Qiu Geng 'destiny community ": worship in the new international view [N] study times, 2015-06-08.

[3] Wang yi. 2015 Chinese foreign building human destiny community big innovations Concept of countries [EB/OL]. The foreign ministry website, 2015-12-12.

[4] Gold should be loyal. Try to talk about human destiny community consciousness, and the theory of symbiosis international society Sex [J]. International observation, 2014 (1).

[5] li ping, growth. The perspective of sports ethics value of building a harmonious society Theory analysis [J]. Journal of physical education and science, 2005 (9) : 26-5.

[6] Luo Hanli Peng Xionghui. Urban community sports present situation and the development countermeasures[J] ,Sports journal, 2004 (1) : 111. 